\title{
Art-making to deepen our understanding of illness
}

\author{
Cite as: CMAJ 2019 February 25;191:E233-4. doi: 10.1503/cmaj.181050
}

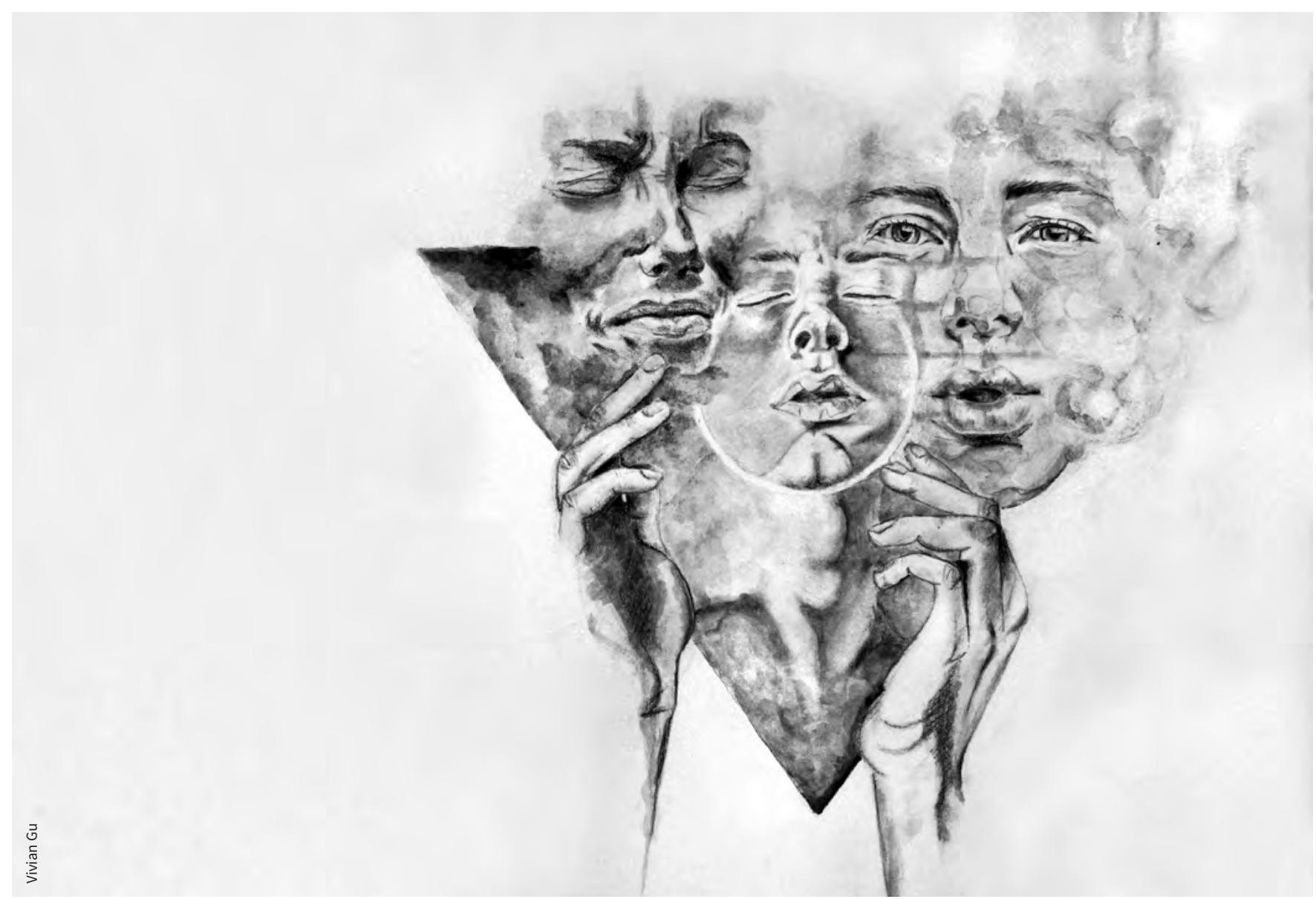

"The Center Cannot Hold" (2017). Watercolour and pencil on paper. $279 \times 432 \mathrm{~cm}$. This piece is inspired by The Center Cannot Hold: My Journey Through Madness, ${ }^{1}$ a memoir on schizophrenia. The author describes psychosis as a disorganization, where your centre gives way; who you are is engulfed in a fog that obscures the solid centre from which you normally see reality. The hands' positioning speaks to losing grip, and the circle of negative space reflects the absence of focus and foundation. The faces represent the author's three identities: herself, her professional identity and her psychotic state. They meld into one another, and it's impossible to extract one without affecting the others, because despite constant denial, the psychosis is part of who she is. The psychotic self (left) looks scared. This reminds us that psychosis is not scary or violent; the person experiencing psychosis is terrified. Lastly, a triangle - the most stable shape - reflects the author's experience of finding stability despite her centre giving way. What struck me most from this reading was the idea that - mental illness or not - all of us are, in our own ways, striving for balance and stability amid our demons.

Ithough much of our current medical education is focused on disease (which is concerned with pathology), we end up spending less time learning about illness - the subjective experience of health and disease. I was interested in deepening my understanding of illness and began a project to explore this further. As part of the curriculum at the University of British Columbia, medical students are given the opportunity to pursue a self-directed scholarly project. This can be in the form of research, community outreach or creative endeavours.

The aim of my project was to build authentic reflective and empathic skills, explore the concept of illness and spark 


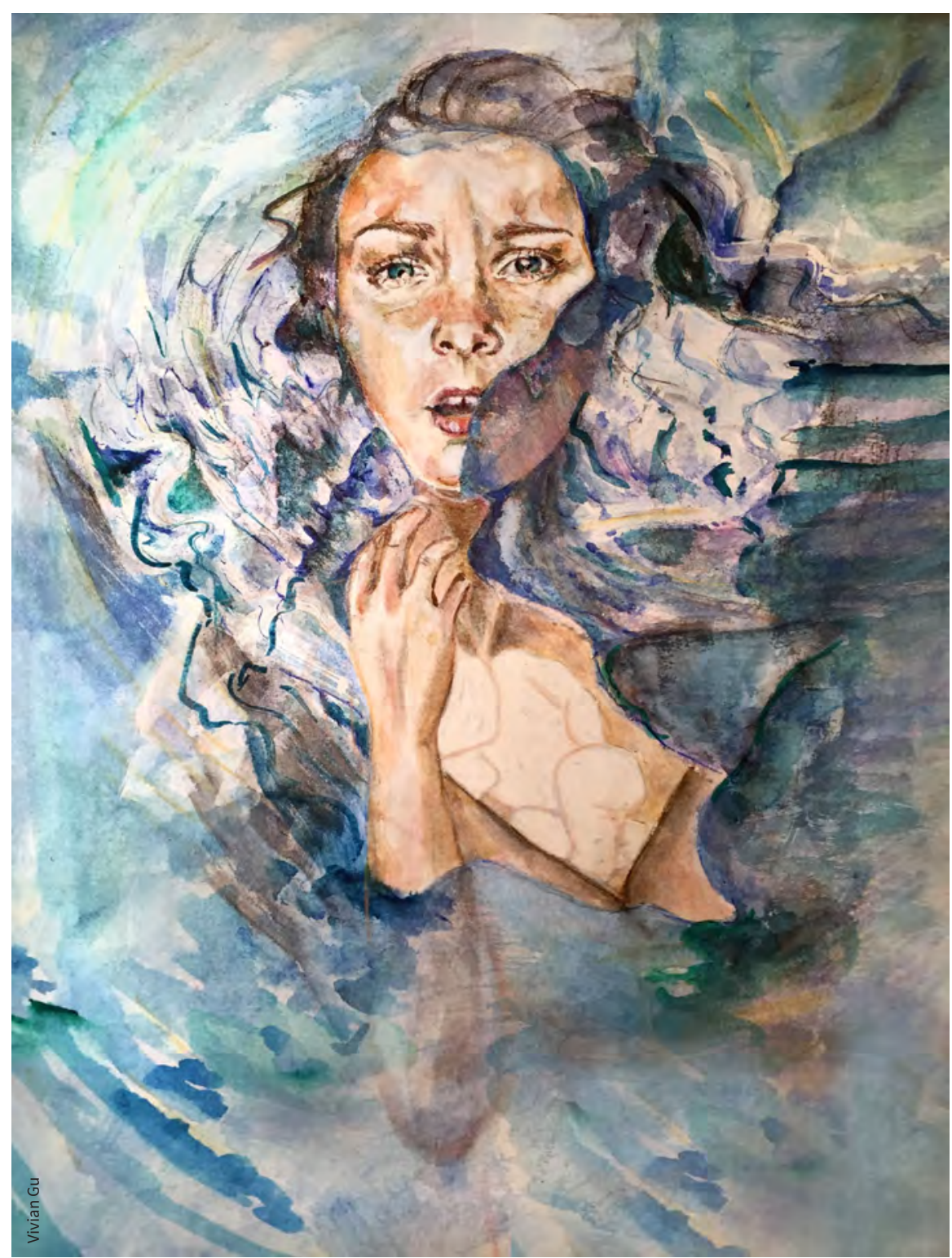

"This is Happy" (2018). Watercolour on paper. $279 \times 432 \mathrm{~cm}$. This piece is inspired by This Is Happy, a memoir on miscarriage and postpartum depression. Underwater, senses become muffled and isolation acute. As breath falls away, a tightness builds and the focus narrows in on one thing: breaking the surface for a breath. This metaphor of being trapped underwater was how I most connected with the author's experience of depression. I remember the visceral sensation of being trapped, isolated in the vastness of the water, as I painted the waves. Beyond this, though, I was struck by the additional facets of postpartum depression. The guilt associated with not meeting "mothering expectations," depicted by the mother clutching her baby close despite her situation and surroundings. The palpable space of absent-yet-expected happiness left by postpartum depression, depicted by the negative space of the baby. Like a pebble in a pond, the ripple effects of mental illness spread beyond the individual experiencing it. dialogue on the value of arts and humanities in medical education. To do so, I read memoirs on illness, as these first-person accounts bring me closer to the experience of illness through storytelling. I then drew on themes and messages that struck me in my reading to create an artwork for each memoir. This creative process was a course of reflection and synthesis, an attempt to better understand and deeply empathize with the patients' lived experiences. I have shared 2 pieces from my collection of 5 , in the hope of sparking reflection and dialogue in viewers.

\section{Vivian Gu BA}

University of British Columbia, Vancouver, BC

\section{References}

1. Saks ER. The center cannot hold: my journey through madness. New York: Hyperion; 2007.

2. Gibb C. This is happy: a memoir. Toronto: Anchor Canada; 2016.

This article has been peer reviewed.

Author's note: These artworks express the artist's views only, and do not represent the views of the memoir authors.

Acknowledgement: The author acknowledges and thanks Carol Ann Courneya for her support, guidance and assistance with this project. Her passion for arts and humanities in medical education is infectious.

Competing interests: None declared. 